SUBJECT AREAS:

ATMOSPHERIC

DYNAMICS

ENVIRONMENTAL HEALTH

Received

5 February 2014

Accepted

16 April 2014

Published

15 May 2014

Correspondence and requests for materials should be addressed to Y.Q. (qiuy@tiosoa.cn)

\section{The asymmetric influence of the positive and negative IOD events on China's rainfall}

\author{
Yun Qiu ${ }^{1,2}$, Wenju Cai ${ }^{2}$, Xiaogang Guo' \& Benjamin $\mathrm{Ng}^{2}$
}

\author{
'The Third Institute of Oceanography, State Oceanic Administration, Xiamen, China, ${ }^{2}$ CSIRO Marine and Atmospheric Research, \\ Aspendale, Victoria, Australia.
}

Rainfall anomalies over southern China are found to be asymmetricly influenced by the Indian Ocean Dipole (IOD), with a far stronger influence from positive IOD (pIOD) events. A greater convection anomaly and an equivalent-barotropic Rossby wave train response occurs during pIOD events than during negative IOD (nIOD) events. Over the Bay of Bengal (BOB) and South China Sea (SCS), an associated low-level anomalous anticyclone strengthens the southwesterlies during boreal fall (September, October and November, SON), when a pIOD matures. The increased moisture flux gives rise to the anomalously high rainfall over southern China. During its developing phase (boreal summer, June, July, and August, JJA), the influence of a pIOD event on the contemporaneous rainfall over southern China is weak, but a JJA pIOD index is highly correlated with fall rainfall. Therefore, this index can serve as a potential predictor for variations of boreal fall rainfall over southern China.

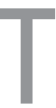

he Indian Ocean Dipole (IOD) is an air-sea coupled climate mode in the Indian Ocean, characterized by opposing sea surface temperature anomalies (SSTAs) in the western and eastern tropical Indian Ocean ${ }^{1-3}$. It not only influences rainfall in the countries around the Indian Ocean, such as Australia, East Africa and Indonesia $a^{4-8}$, but also affects climate variability over remote areas, such as East Asia, Europe and South America ${ }^{9-12}$. The associated atmospheric teleconnection carries the impact to regions remote from the source region $^{13,14}$. The Indian Ocean influences monsoon variability over East Asia via an eastern Indian Ocean/west Pacific route, through Rossby wave trains, similar to the Pacific-North American (PNA) patterns ${ }^{15-17}$.

Many studies have examined the influence of the IOD on the East Asian summer monsoon and China's summer rainfall ${ }^{18}$. It is suggested that different phases of the IOD mode may change the intensity of the South Asian High (SAH) and the western North Pacific anticyclone in summer, and hence variations of monsooninduced rainfall over China ${ }^{9,19}$. In contrast, relatively less attention has been paid to the role of the IOD on the variations of rainfall over China during boreal fall, when the IOD peaks. A recent study ${ }^{20}$ showed peak SSTAs for the IOD appear in fall and possess a stronger link to the Asian winter monsoon than to the Asian summer monsoon. It is suggested that this far-reaching influence during boreal winter is conducted through a wave train that is emanated from the Indo-Western Pacific and induced by heating anomalies in this region ${ }^{21}$.

Recent studies ${ }^{17,22}$ have shown that there is an asymmetry between positive and negative IOD events (i.e. pIOD and nIOD), with pIOD events reducing rainfall over southern Australia significantly more than a rainfall increase from nIOD events. This "impact asymmetry" is consistent with a positive skewness of the $\mathrm{IOD}^{6,17,23}$. However, it remains unclear how atmospheric circulation over East Asia and rainfall over China respond to the IOD amplitude asymmetry. This study examines these issues, and the associated mechanisms.

\section{Results}

Composite Analysis. The atmospheric circulation over China during warm seasons is characterized by the monsoon system ${ }^{18}$. Southwesterlies from the Indian Ocean and South China Sea (SCS) advect a large amount of moisture to much of China, where rainfall seasonality shows a peak in boreal summer (Fig. 1a). In boreal fall (Fig. 1d), an anticyclone flow pattern operates over southern China. The easterly wind to its south and the southwesterly wind to its west, converge over southern China, carrying water vapor from the tropical oceans. These two moisture transport branches supply the fall rainfall over southern China: one is from the Bay of Bengal $(\mathrm{BOB})$ and the other is from the SCS; they originate from the Indian Ocean and the west Pacific, respectively. 
a JJA: mean rain \& wind

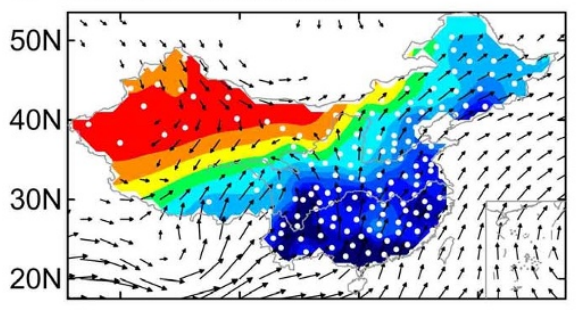

b JJA: anomalous rain \& wind during pIOD

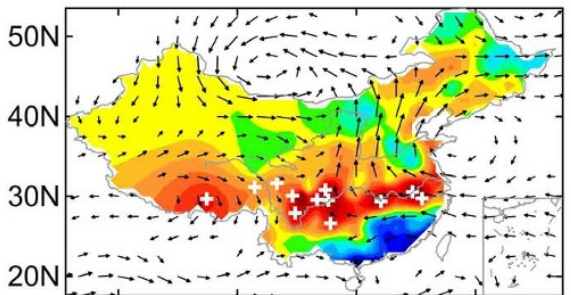

c JJA: anomalous rain \& wind during $\mathrm{nIOD}$

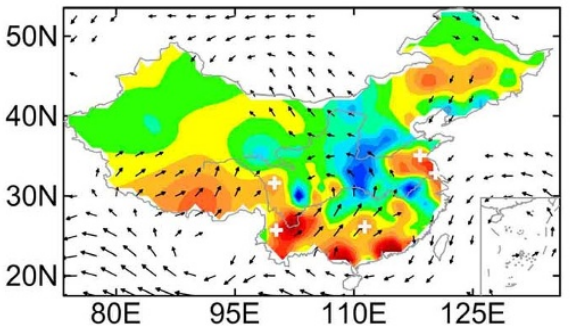

d SON: mean rain \& wind

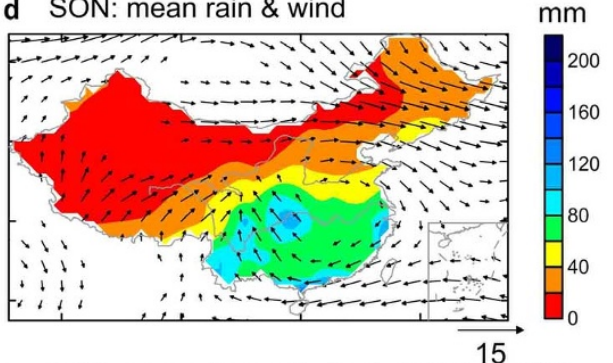

e SON: anomalous rain \& wind during pIOD

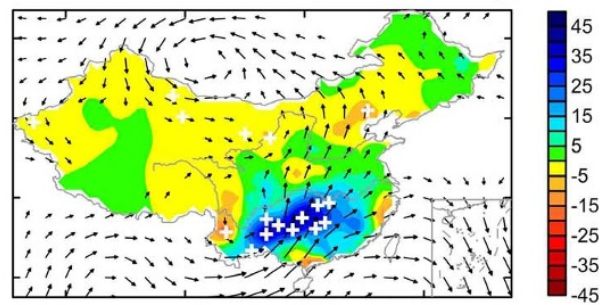

f SON: anomalous rain \& wind during nIOD

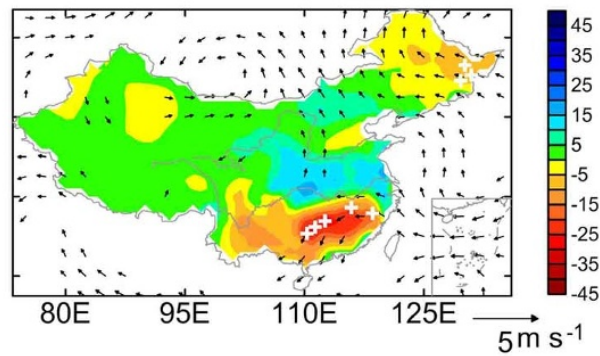

Figure $1 \mid$ China boreal summer (JJA) and fall (SON) rainfall and surface wind vectors. (a), Climatology JJA rainfall (shading) and 850 hPa wind (arrows, maximum vector denotes a value of $15 \mathrm{~m} \mathrm{~s}^{-1}$, and vectors smaller than $1.5 \mathrm{~m} \mathrm{~s}^{-1}$ are not plotted). (b), Composite JJA rainfall anomalies (shading) and $850 \mathrm{hPa}$ wind anomaly (arrows, maximum vector denotes a value of $5 \mathrm{~m} \mathrm{~s}^{-1}$, and vectors smaller than $0.3 \mathrm{~m} \mathrm{~s} \mathrm{~s}^{-1}$ are not plotted) for the four pure pIOD years $(1961,1967,1983$, and 1994). (c), As in (b) but for the seven pure nIOD years $(1958,1968,1974,1980,1985,1989$, and 1992). (d), (e), and (f), As in (a), (b), and (c), respectively, but for SON. White stipples indicate anomalous rainfall is greater than $95 \%$ confidence level. All plots were produced using licensed Surfer.

In order to understand the IOD's influence on China's climate, composite rainfall and $850-\mathrm{hPa}$ wind anomalies for the pIOD and nIOD years are constructed. Based on the classification of a previous study ${ }^{24}$, the cases of 1961, 1967, 1983 and 1994 in the positive phase and those of 1958, 1968, 1974, 1980, 1985, 1989 and 1992 in the negative phase are chosen for pure IOD years (without El NiñoSouthern Oscillation, i.e. ENSO events). The rainfall anomaly composites of pure pIOD events show that rainfall is above normal over southern China (i.e., about south of $28^{\circ} \mathrm{N}$ ), while less rainfall occurs over the other parts of China during boreal summer (Fig. 1b). In contrast, excessive rainfall occurs in most parts of central and southern China (i.e., about south of $38^{\circ} \mathrm{N}$ and east of $100^{\circ} \mathrm{E}$ ), while rainfall is below normal in northern China (i.e., about north of $38^{\circ} \mathrm{N}$ ) during boreal fall (Fig. 1e). In the pure nIOD years, central China (especially the middle reaches of the Yangtze River Valley and the Great Band of the Yellow River) experiences a wet summer, but rainfall in southern and most parts of northern China declines (Fig. 1c). The fall rainfall pattern is almost reversed to a dipole pattern with negative rainfall anomalies over southern China but positive anomalies over central and northern China (Fig. 1f). Such a summer IOD-rainfall connection is also reported in previous studies ${ }^{15,25}$.

To further quantify the statistical relation between the IOD and China's rainfall, correlation analysis is carried out using the dipole mode index (DMI) ${ }^{1}$ and rainfall anomalies (Fig. 2). Regarding ENSO events that are related to the $\mathrm{IOD}^{17,26}$, in order to isolate ENSO effects, a linear relation of Niño-3.4 with the DMI has been removed from the DMI, to obtain a residual index (i.e., DMI $\left.\right|_{\text {Niño-3.4 }}$ ). As the IOD is weaker in boreal summer compared with boreal fall, no obvious correlation between DMI $\left.\right|_{\text {Niño-3.4 }}$ and rainfall anomalies during summer is observed (Fig. 2a). However, it still shows that the positive phase of the IOD is conducive to a summer rainfall increase in southern China while the corresponding negative phase leads to a decrease in summer rainfall over the same region, which is consistent to the composite analyses (Figs. $1 \mathrm{~b}$ and 1c). As the IOD peaks in boreal fall, it has a strong influence on the contemporaneous rainfall variations over southern China (Fig. 2c), with correlation coefficients significant at the $95 \%$ confidence level.

Although the influence of the IOD in its developing phase on summer rainfall over southern China is weak, its influence on fall rainfall (i.e., rainfall lags the $\left.\mathrm{DMI}\right|_{\text {Niño-3.4 }}$ by one season) strengthens substantially (Fig. 2b). A strong positive relationship between JJA $\left.\mathrm{DMI}\right|_{\text {Niño-3.4 }}$ and SON DMI $\left.\right|_{\text {Niño-3.4 }}$ (Fig. 2d) suggests that the anomalous response of fall rainfall over southern China mainly comes from the peaking phase (i.e., SON) of the IOD, because strong JJA $\left.\mathrm{DMI}\right|_{\text {Niño-3.4 }}$ tends to be associated with strong SON DMI $\left.\right|_{\text {Niño-3.4. }}$ Consistently, a previous study ${ }^{20}$ has shown that the matured IOD phase has a stronger link to the Asian winter monsoon than to the Asian summer monsoon. These results suggest an important point that the JJA DMI $\left.\right|_{\text {Niño-3.4 }}$ can serve as a potential predictor for fall rainfall over southern China.

Asymmetric relationship with SON rainfall and its teleconnection. To highlight the asymmetry in the relationship between SON rainfall and the opposite phases of the IOD, a scatterplot of SON 

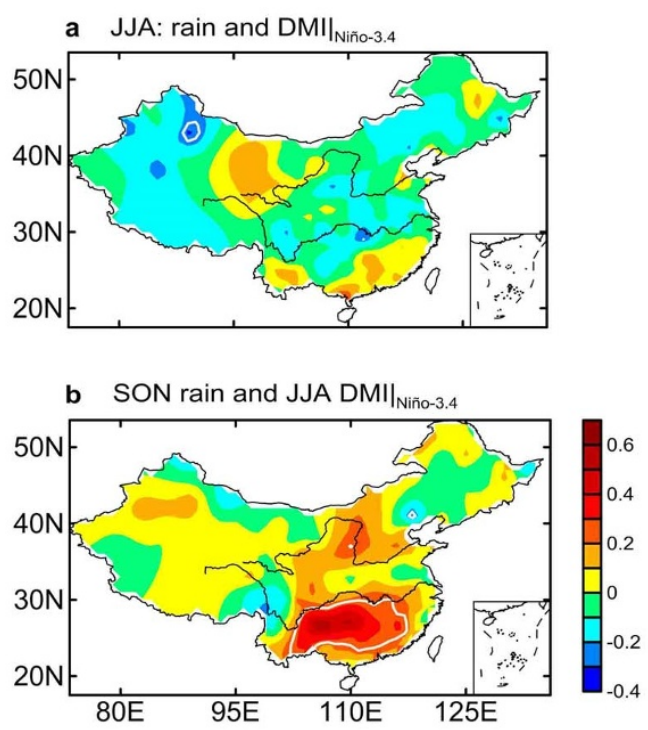

C SON: rain and DMI| $\left.\right|_{\text {Niño-3.4 }}$

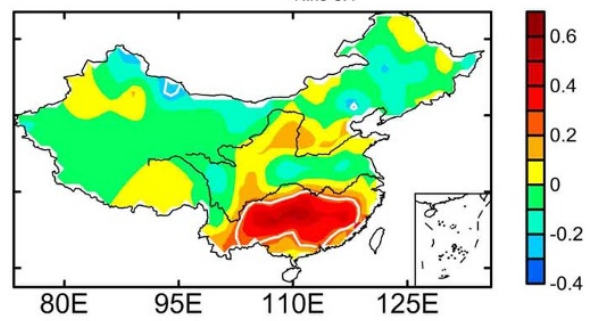

d JJA DMI| $\left.\right|_{\text {Niño-3.4 }}$ vs SON DMI| $\left.\right|_{\text {Niño-3.4 }}$

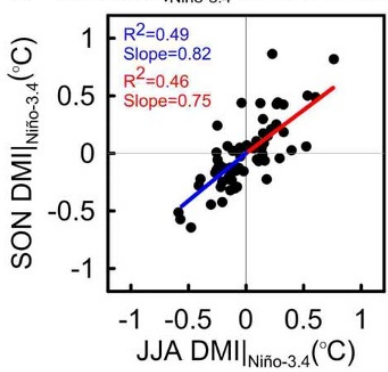

Figure $2 \mid$ Relationship of rainfall with the IOD. (a), Correlation pattern between JJA rainfall and JJA IOD index (DMI), upon removal of a linear relation with the Niño-3.4 index (i.e., DMI $\left.\right|_{\text {Niño-3.4 }}$ ). (b), (c), As in (a) but for SON rainfall and JJA DMI $\left.\left.\right|_{\text {Niño-3.4, and for SON rainfall and SON DMI }}\right|_{\text {Niño-3.4, }}$ respectively. (d), Scatterplot of linearly detrended SON DMI $\left.\right|_{\text {Niño-3.4 }}$ against JJA DMI $\left.\right|_{\text {Niño-3.4. }}$ Two sets of linear regression statistics (correlation and slope) are shown in (d), using samples with a positive JJA DMI $\left.\right|_{\text {Niño-3.4 }}\left(\right.$ red), and samples with a negative JJA DMI $\left.\right|_{\text {Niño-3.4 }}$ (blue). Areas within white curves in (a), (b), and (c) indicate correlations that are significant at the $95 \%$ confidence level. (a), (b), and (c) are plotted using licensed Surfer. (d) is plotted using licensed Grapher.

$\left.\mathrm{DMI}\right|_{\text {Niño-3.4 }}$ values versus contemporaneous rainfall anomalies averaged over southern China is shown in Fig. 3. For positive $\left.\mathrm{DMI}\right|_{\text {Niño-3.4 }}$ values, rainfall anomalies tend to be positive (although some weak negative values are present), suggesting an increase in rainfall, while during nIODs, most rainfall anomalies are negative. The influence of a pIOD on rainfall increases is far greater than that of a nIOD on rainfall decreases, as indicated by a far greater slope during pIOD events. Thus, there is an asymmetry between positive and negative events, with a PIOD increasing rainfall over southern China significantly more than the rainfall decrease

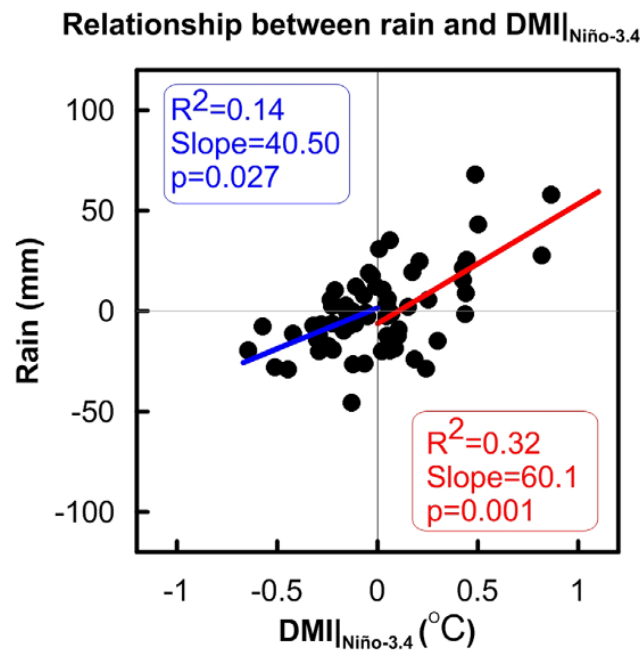

Figure $3 \mid$ Response of the China SON rainfall to the SON DMI $\left.\right|_{\text {Niño-3.4. }}$ Scatterplot of linearly detrended SON rainfall anomalies averaged over southern China $\left(103^{\circ}-109^{\circ} \mathrm{E}, 24^{\circ}-28^{\circ} \mathrm{N}\right)$ against the SON DMI $\left.\right|_{\text {Niño-3.4 }}$. Two sets of linear regression statistics (correlation, slope, and $p$ value) are shown, using samples with a positive DMI $\left.\right|_{\text {Niño-3.4 }}(\mathrm{red})$, and samples with a negative DMI $\left.\right|_{\text {Niño-3.4 }}$ (blue). The plot was produced using licensed Grapher. from the negative phase events, which is probably induced by an amplitude asymmetry between the different phases of the IOD (i.e. IOD skewness) $)^{17,27-29}$.

What is the relationship between the IOD skewness and the asymmetric response of southern China rainfall to the IOD? To examine this, we regress grid-point convection and circulation anomalies onto the DMI $\left.\right|_{\text {Niño-3.4. First, we construct their linear relationship using all }}$ samples (Figs. 4a-4c). Results show a tropically trapped baroclinic response to diabatic heating (convective) anomalies over the east/ west IOD pole (IODE/IODW), extending northward to the BOB and the SCS from the IODE region, to the Arabian Sea from the IODW region, respectively (Figs $4 \mathrm{a}, \mathrm{b}$ ). Additionally, in response to the convective anomalies over the IOD poles, an eastern Indian Ocean and a western Indian Ocean Rossby wave train (Fig. 4a), share a low pressure anomaly center stretching from the Tibetan Plateau to the northwestern Pacific (Fig. 4b). These Rossby wave-train patterns have also been suggested in previous studies ${ }^{15,16}$. The low pressure center suggests a weaker SAH than normal. The weaker SAH supports a stronger-than-normal summer monsoon over the $\mathrm{BOB}$ and $\mathrm{SCS}^{19}$. Consistently, anomalous SON southwesterlies in association with the weaker SAH, reach southern China via the BOB and SCS (Figs. 5b, 5d), leading to anomalously high rainfall over southern China (Fig. 4c).

Then, we focus on asymmetry with respect to pIOD and nIOD events. We use samples with a positive DMI $\left.\right|_{\text {Niño-3.4 }}$, or negative $\left.\mathrm{DMI}\right|_{\text {Niño-3.4 }}$ only in our regression. Circulation anomalies associated with pIODs (Figs. $4 \mathrm{~d}$ and $4 \mathrm{e}$ ) are better defined than those associated with nIODs (Figs. $4 \mathrm{~g}$ and $4 \mathrm{~h}$ ). This is evident by the presence of stronger outgoing longwave radiation (OLR) anomalies over the tropics, with corresponding well-defined extratropical wave train patterns associated with pIOD events. In fact, much of the wave train pattern obtained using all samples (Figs. $4 \mathrm{a}$ and $4 \mathrm{~b}$ ) is contributed by pIOD events (Figs. $4 \mathrm{~d}$ and $4 \mathrm{e}$ ). There is virtually no such signal in anomaly patterns associated with nIOD events (Figs. $4 \mathrm{~g}$ and $4 \mathrm{~h}$ ). This asymmetry translates into a direct influence on southern China's fall rainfall: the size of positive rainfall anomalies over southern China systematically increases with pIOD amplitude (Figs. 3 and 4f). In 
a Regression of OLR onto DMI

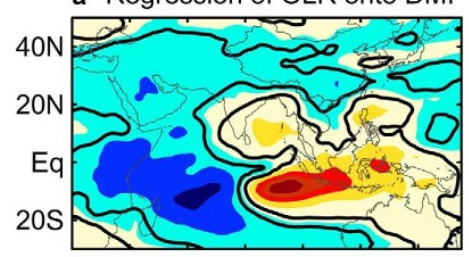

d Regression of OLR onto $\mathrm{pDM}$

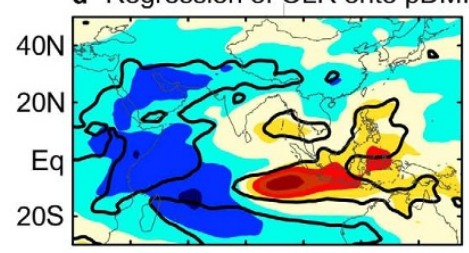

g Regression of OLR onto $\mathrm{nDMI}$

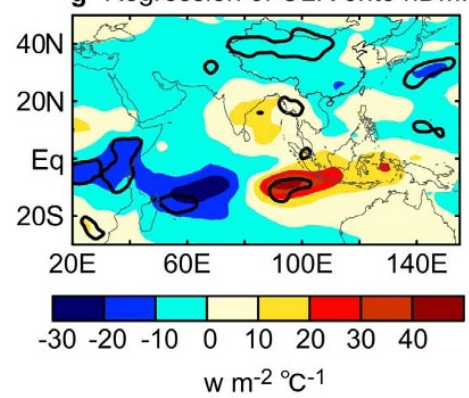

b Regression of $\mathrm{GH}$ onto DMI

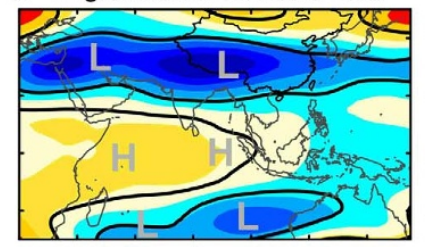

e Regression of $\mathrm{GH}$ onto pDMI

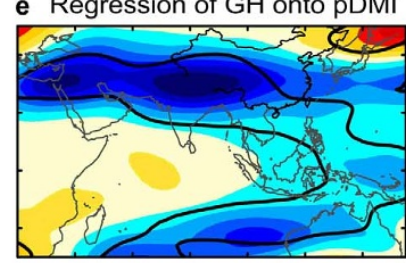

h Regression of $\mathrm{GH}$ onto $\mathrm{nDMI}$
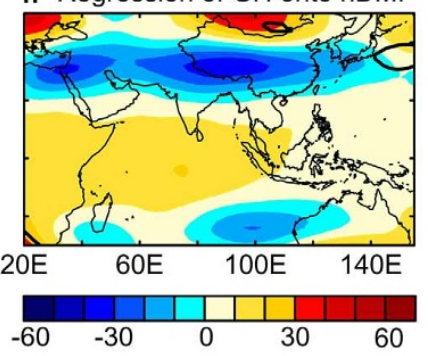

$\mathrm{m}{ }^{\circ} \mathrm{C}^{-1}$

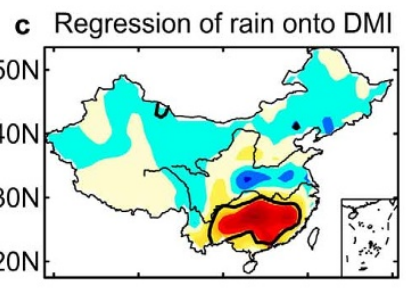

f Regression of rain onto pDMI

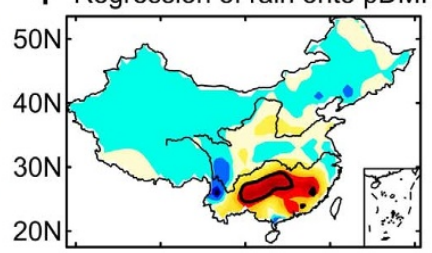

i Regression of rain onto $\mathrm{nDMI}$

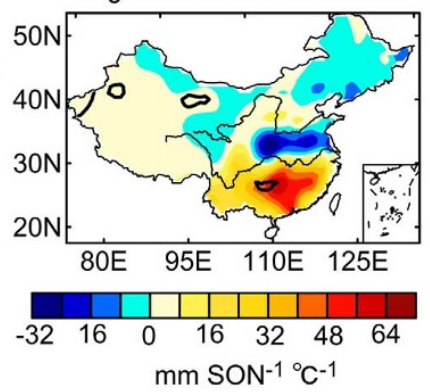

Figure $4 \mid$ Response patterns of circulation to the IOD events. (a), (b), and (c), Circulation anomaly patterns obtained by regressing detrended circulation anomalies onto a detrended DMI $\left.\right|_{\text {Niño-3.4 }}$ using all samples averaged over SON, which implies a linear response. (d), (e), and (f), As in (a), (b), and (c), respectively, but for samples with positive DMI $\left.\right|_{\text {Niño-3.4 }}$ values (pDMI $\left.\right|_{\text {Niño-3.4 }}$ ). (g), (h), (i), As in (a), (b), and (c), respectively, but for samples with negative $\left.\mathrm{DMI}\right|_{\text {Niño-3.4 }}$ values $\left(\left.\mathrm{nDMI}\right|_{\text {Niño-3.4 }}\right)$. The shading represents the regression coefficients and areas within the thick black contours indicate significant correlations at the 95\% confidence level. (a), (d), and (g), show the coefficients associated with outgoing longwave radiation (OLR). In (b), (e), and (h), are 200-hPa geopotential height $(\mathrm{GH})$, and in (c), (f), and (i), are rainfall over China. "H" and "L" are marked in (b) to illustrate an eastern Indian Ocean and a western Indian Ocean Rossby wave train anomaly centres associated with the IOD. All plots were produced using licensed Surfer.

contrast, the size of negative rainfall anomalies across the same region does not respond to changes in nIOD amplitude in any statistically significant manner (Figs. 3 and 4i), as the relationship between them is not significant at the $95 \%$ confident level.

To further understand the connection of southern China's rainfall with IOD events, and to evaluate the associated atmospheric moisture transportation processes, wind anomaly patterns are constructed by composite analysis (Fig. 5). An asymmetry in wind anomalies is also shown, with anomalies far stronger for the pIOD samples than for the nIOD years (comparing Figs. 5c-5d to Figs. $5 \mathrm{e}-$ 5f). Consistent with the response to tropical diabatic heating described in Figs. 4a and 4d, a strong cyclonic anomaly can be found in the upper troposphere over the Tibetan Plateau and southwestern China (Figs. 5a and 5c), suggesting a weakening of the upper-level tropical easterly winds and anticyclone (i.e. the SAH). On the other hand, at $850 \mathrm{hPa}$, we find an anomalous anti-cyclonic circulation extending northeastward from the BOB to the SCS and southern China (Figs. $5 \mathrm{~b}$ and $5 \mathrm{~d}$ ). This is consistent with finding of a previous study $^{20}$, although their result is based on the data during July to September. This circulation anomaly enhances moist southwestly winds that blow northward from the BOB and the SCS to southern China, facilitating the surplus rainfall over this region.

\section{Discussion}

We have examined the influence of the IOD on China's rainfall during the boreal summer and fall seasons. The results show an asymmetry in the impact of pIOD and nIOD events in terms of an extratropical response. We find that the extratropical circulation response, which is delivered via Rossby wave trains, is greater during
pIOD events than during nIOD events. During pIOD events, the associated low-level anomalous anticyclone found over the BOB and the SCS strengthens the southwesterlies. This leads to an increased moisture flux that gives rise to the anomalously high precipitation over southern China. During nIOD events, the Indian Ocean wave train response is far weaker and less well defined.

The concurrent impact of the JJA DMI $\left.\right|_{\text {Niño-3.4 }}$ on China's summer rainfall is weak. However, it has a strong influence on rainfall in the ensuing SON season. In fact, the JJA DMI $\left.\right|_{\text {Niño-3.4 }}$ has a comparable relationship with SON rainfall to that of the SON DMI $\left.\right|_{\text {Niño-3.4 }}$ with SON rainfall. JJA DMI $\left.\right|_{\text {Niño-3.4 }}$ and SON rainfall possesses a nonlinear relationship, with a JJA positive $\left.\mathrm{DMI}\right|_{\mathrm{Niño-3.4}}$ indicating a stronger SON rainfall signal than that reflected by a JJA negative $\left.\mathrm{DMI}\right|_{\text {Niño-3.4. }}$ In this sense, the JJA DMI $\left.\right|_{\text {Niño-3.4 }}$ serves as a potential forecaster for the variations of fall rainfall over southern China.

\section{Methods}

Data. NCEP/NCAR Reanalysis ${ }^{30}$ monthly data are used to analyze atmospheric circulations that bridge the IOD impacts with climate variability in China. The IOD is described using the dipole mode index $(\mathrm{DMI})^{1}$, defined as the difference of the areaaveraged SST anomalies in the west IOD pole (IODW, $10^{\circ} \mathrm{S}-10^{\circ} \mathrm{N}, 50^{\circ}-70^{\circ} \mathrm{E}$ ) and the east IOD pole (IODE, $10^{\circ} \mathrm{S}-\mathrm{Eq}, 90^{\circ}-110^{\circ} \mathrm{E}$ ). A monthly in-situ precipitation dataset of 160 stations in China (Fig. 1a, white points) from the National Climate Center of the China Meteorological Administration is also used to explore the IOD-rainfall relationship. All data are in the period of 1951-2012, and monthly anomalies are departures from their respective mean values averaged over this period. The monthly anomaly data are then linearly detrended and averaged over the seasonal months to obtain the seasonal anomaly data.

Analysis technique. The basic analysis technique used in this study is linear regression (or equivalently, correlation). Before regression analysis, in order to exclude ENSO effects, a linear relation of Niño-3.4 with the DMI is removed from the 
a $200 \mathrm{hPa}$ wind during IOD years

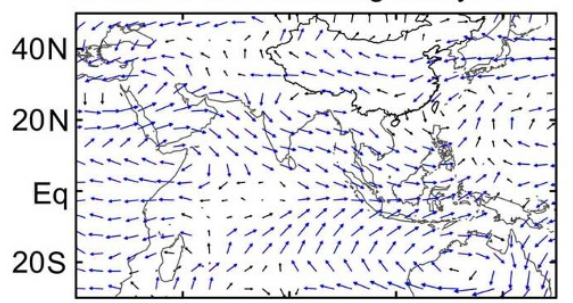

c $200 \mathrm{hPa}$ wind during pIOD years

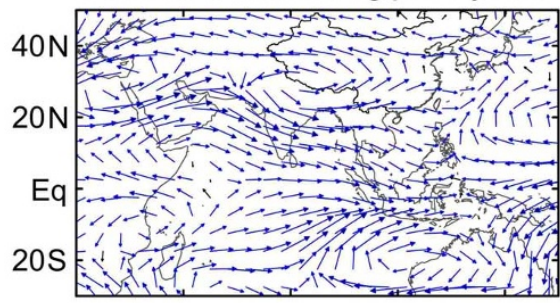

e $200 \mathrm{hPa}$ wind during $\mathrm{nIOD}$ years

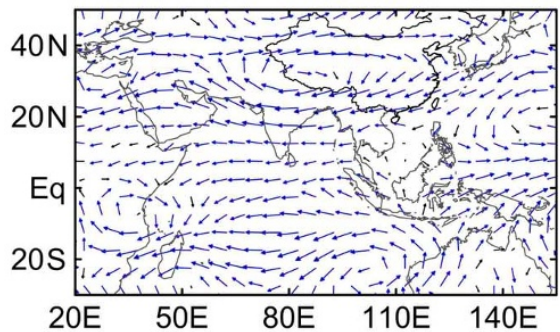

b $850 \mathrm{hPa}$ wind during IOD years

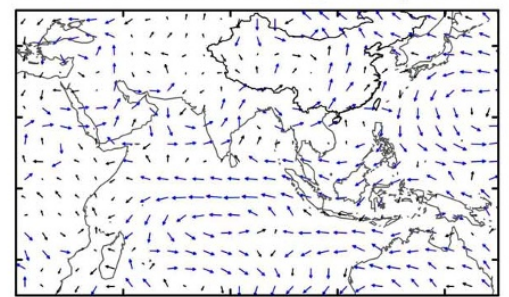

d $850 \mathrm{hPa}$ wind during pIOD years

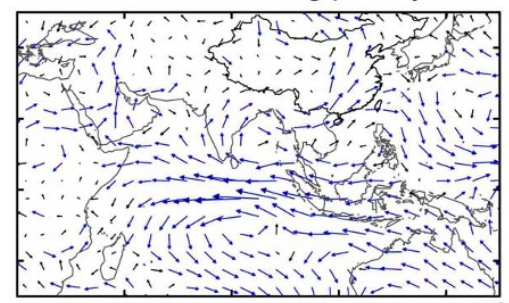

f $850 \mathrm{hPa}$ wind during nIOD years 3

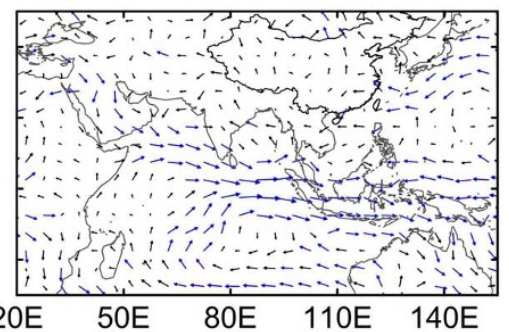

Figure 5 Boreal fall (SON) 200-hPa and 850-hPa winds during pure IOD years. (a), Composite SON 200-hPa wind anomalies (arrows, maximum vector denotes a value of $6.0 \mathrm{~m} \mathrm{~s}^{-1}$, and vectors larger than or equal to $0.5 \mathrm{~m} \mathrm{~s}^{-1}$ are plotted in blue while anomalies smaller than $0.5 \mathrm{~m} \mathrm{~s}{ }^{-1}$ in black) for the 11 pure IOD years (i.e., including the four pure pIOD years (1961, 1967, 1983, and 1994), and the seven pure nIOD years (1958, 1968, 1974, 1980, 1985, 1989, and 1992)). (c), (e), As in (a), but for the pure pIOD years and the pure nIOD years, respectively. (b), (d), and (f), As in (a), (c), and (e), but for 850-hPa winds, respectively. All plots were produced using licensed Surfer.

DMI to obtain a residual index (i.e., DMI $\left.\right|_{\text {Niño-3.4). }}$ Regression coefficients (and the corresponding correlations) are first calculated by regressing anomalous circulation fields onto the DMI $\left.\right|_{\text {Niño-3.4 }}$ using all samples, assuming a symmetric response with respect to positive and negative phases. Regression coefficients are then calculated using samples containing only pIOD or only nIOD values. Statistical significance of the regression anomalies is estimated based on significance of the associated correlation coefficients, which is when $\mathrm{p}$ value $<0.05$.

Seasonality. All calculations in this paper are based on data in boreal summer (June, July, and August, or JJA) and in boreal fall (September, October, and November, or SON), when IOD events develop and peak respectively.

Graphic software. All maps and plots were produced using licensed Surfer or Grapher.

1. Saji, N. H., Goswami, B. N., Vinayachandran, P. N. \& Yamagata, T. A dipole mode in the tropical Indian Ocean. Nature 401, 360-363 (1999).

2. Du, Y., Cai, W. \& Wu, Y. L. A new type of the Indian Ocean Dipole since the mid1970s. J. Clim. 26, 959-972 (2013).

3. Webster, P. J., Moore, A. M., Loschnigg, J. P. \& Leben, R. R. Coupled oceanatmosphere dynamics in the Indian Ocean during 1997-98. Nature 401, 356-360 (1999).

4. Black, E., Slingo, J. \& Sperber, K. R. An observational study of the relationship between excessively strong short rains in coastal East Africa and Indian Ocean SST. Mon. Wea. Rev. 131, 74-94 (2003).

5. Clark, C. O., Webster, P. J. \& Cole, J. E. Interdecadal variability of the relationship between the Indian Ocean zonal mode and East African coastal rainfall anomalies. J. Clim. 16, 548-554 (2003)

6. Cai, W., Cowan, T. \& Sullivan, A. Recent unprecedented skewness towards positive Indian Ocean Dipole occurrences and its impact on Australian rainfall. Geophys. Res. Lett. 36, L11705, doi: 10.1029/2009GL037604 (2009).

7. Ashok, K., Guan, Z. \& Yamagata, T. Influence of the Indian Ocean Dipole on the Australian winter rainfall. Geophys. Res. Lett. 30, L1821 (2003).

8. Ummenhofer, C. C. et al. What causes southeast Australia's worst droughts? Geophys. Res. Lett. 36, L04706 (2009).
9. Yuan, Y., Yang, H., Zhou, W. \& Li, C. Influences of the Indian Ocean Dipole on the Asian summer monsoon in the following year. Int. J. Climatol. 28, 1849-1859 (2008).

10. Saji, N. H. \& Yamagata, T. Possible impacts of Indian Ocean dipole mode events on global climate. Climate Res. 25, 151-169 (2003).

11. Chan, S. C., Behera, S. K. \& Yamagata, T. Indian Ocean Dipole influence on South American rainfall. Geophys. Res. Lett. 35, L14S12, doi: 10.1029/2008GL034204 (2008).

12. Kripalani, R. H., Oh, J. H. \& Chaudhari, H. S. Delayed influence of the Indian Ocean Dipole mode on the East Asia-West Pacific monsoon: possible mechanism. Int. J. Climatol. 30, 197-209 (2010).

13. Behera, S. K., Luo, J. J., Masson, S., Delecluse, P., Gualdi, S., Navarra, A. \& Yamagata, T. Paramount Impact of the Indian Ocean Dipole on the East African Short Rains: A CGCM Study. J. Clim. 18, 4514-4530 (2005).

14. Cai, W., Rensch, P., Cowan, T. \& Hendon, H. H. Teleconnection Pathways of ENSO and the IOD and the Mechanisms for Impacts on Australian Rainfall. J. Clim. 24, 3910-3923 (2011).

15. Guan, Z. \& Yamagata, T. The unusual summer of 1994 in East Asia: IOD teleconnections. Geophys. Res. Lett. 30 (10), 1544, doi: 10.1029/2002GL016831 (2003).

16. Kripalani, R. H., Oh, J.-H., Kang, J.-H., Sabade, S. S. \& Kulkarni, A. Extreme monsoons over East Asia: Possible role of Indian Ocean Zonal Mode. Theor. Appl. Climatol. 82, 81-94. doi: 10.1007/s00704-004-0114-z (2005).

17. Cai, W., Rensch, P., Cowan, T. \& Hendon, H. H. An asymmetry in the IOD and ENSO teleconnection pathway and its impact on Australian climate. J. Clim. 25, 6318-6329 (2012).

18. Ding, Y. \& Chan, J. C. L. The East Asian summer monsoon: an overview. Meteorol. Atmos. Phys. 89, 117-142. doi: 10.1007/s00703-005-0125-z (2005).

19. Li, C. \& Mu, M. The influence of the Indian Ocean dipole on atmospheric circulation and climate. Adv. Atmos. Sci. 18, 831-843 (2001).

20. Yang, J. L., Liu, Q. \& Liu, Z. Linking Observations of the Asian Monsoon to the Indian Ocean SST: Possible Roles of Indian Ocean Basin Mode and Dipole Mode. J. Clim. 23, 5889-5902 (2010)

21. Zheng, J., Liu, Q., Wang, C. \& Zheng, X.-T. Impact of heating anomalies associated with rainfall variations over the Indo-Western Pacific on Asian atmospheric circulation in winter. Clim. Dyn. 40, 2023-2033 (2013). 
22. Weller, E. \& Cai, W. Asymmetry in the IOD and ENSO Teleconnection in a CMIP5 Model Ensemble and Its Relevance to Regional Rainfall. J. Clim. 26, 5139-5149. doi: http://dx.doi.org/10.1175/JCLI-D-12-00789.1 (2013).

23. Cai, W. \& Qiu, Y. An observation-based assessment of nonlinear feedback processes associated with the Indian Ocean Dipole. J. Clim. 26, 2880-2890 (2013).

24. Meyers, G., McIntosh, P., Pigot, L. \& Pook, M. The Years of El Niño, La Niña, and Interactions with the Tropical Indian Ocean. J. Clim. 20, 2872-2880. doi: http:// dx.doi.org/10.1175/JCLI4152.1 (2007).

25. Ashok, K., Guan, Z. \& Yamagata, T. Impact of the Indian Ocean Dipole on the Decadal Relationship between the Indian Monsoon Rainfall and ENSO. Geophys. Res. Lett. 28, 4499-4502 (2001).

26. Luo, J. J. et al. Interaction between El Niño and Extreme Indian Ocean Dipole. J. Clim. 23, 726-742 (2010).

27. Hong, C. C., Li, T., Lin, H. \& Kug, J. S. Asymmetry of the Indian Ocean dipole. Part I: Observational analysis. J. Clim. 21, 4834-4848 (2008).

28. Zheng, X. T., Xie, S. P., Vecchi, G. A., Liu, Q. \& Hafner, J. Indian Ocean dipole response to global warming: Analysis of ocean-atmospheric feedbacks in a coupled model. J. Clim. 23, 1240-1253 (2010).

29. Ogata, T., Xie, S.-P., Lan, J. \& Zheng, X. Importance of ocean dynamics for the skewness of the Indian Ocean Dipole mode. J. Clim. 26, 2145-2159 (2013).

30. Kalnay, E. et al. The NCEP/NCAR 40-Year Reanalysis Project. Bull. Amer. Meteor. Soc. 77, 437-471 (1996).

\section{Acknowledgments}

This work was carried out while Y.Q. was visiting CSIRO. Y.Q. and X.G. are supported by the National Natural Science Foundation (Grant No. 41276034 and 40806014), the Chinese
Ministry of Science and technology through the National Basic Research Program (Grant No. 2011CB403502), and Scientific Research Foundation of Third Institute of

Oceanography, SOA (Grant No. TIO2008014). W.C. and B.N. are supported by the Australian Climate Change Science Programme, The Goyder Institute, and the CSIRO Wealth from Oceans National Research Flagship.

\section{Author contributions}

Y.Q. and W.C. conceived and designed the analysis. Y.Q. conducted the analysis. Y.Q., W.C., X.G. and B.N. wrote the manuscript together.

\section{Additional information}

Competing financial interests: The authors declare no competing financial interests.

How to cite this article: Qiu, Y., Cai, W.J., Guo, X.G. \& Ng, B. The asymmetric influence of the positive and negative IOD events on China's rainfall. Sci. Rep. 4, 4943; DOI:10.1038/ srep04943 (2014).

This work is licensed under a Creative Commons Attribution-NonCommercialNoDerivs 3.0 Unported License. The images in this article are included in the article's Creative Commons license, unless indicated otherwise in the image credit; if the image is not included under the Creative Commons license, users will need to obtain permission from the license holder in order to reproduce the image. To view a copy of this license, visit http://creativecommons.org/licenses/by-nc-nd/3.0/ 